\title{
Growth and Characterization of $\mathrm{ZrB}_{2}$ Thin Films
}

\section{Lina Tengdelius}

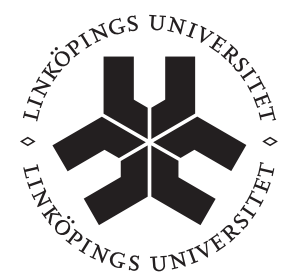

\section{Linköping University INSTITUTE OF TECHNOLOGY}

LIU-TEK-LIC-2013:48

Thin Film Physics Division

Department of Physics, Chemistry and Biology

Linköping University, SE-581 83 Linköping, Sweden 
(C) Lina Tengdelius

ISBN: 978-91-7519-532-2

ISSN: 0280-7971

Printed by LiU-Tryck

Linköping, Sweden, 2013 


\section{Abstract}

In this thesis, growth of $\mathrm{ZrB}_{2}$ thin films by direct current magnetron sputtering is investigated using a high vacuum industrial scale deposition system and an ultra-high vacuum laboratory scale system. The films were grown from $\mathrm{ZrB}_{2}$ compound targets at temperatures ranging from ambient (without external heating) to $900{ }^{\circ} \mathrm{C}$ and with substrate biases from -20 to $-120 \mathrm{~V}$. Short deposition times of typically 100 or $300 \mathrm{~s}$ and high growth rates of $80-180 \mathrm{~nm} / \mathrm{min}$ were emphasized to yield films with thicknesses of 300-400 nm. The films were characterized by thin film X-ray diffraction with the techniques $\theta / 2 \theta$ and $\omega$ scans, pole figure measurements and reciprocal space mapping, scanning and transmission electron microscopy, elastic recoil detection analysis and four point probe measurements. The substrates applied were $\operatorname{Si}(100), \operatorname{Si}(111)$, $4 \mathrm{H}-\mathrm{SiC}(0001)$ and $\mathrm{GaN}(0001)$ epilayers grown on $4 \mathrm{H}-\mathrm{SiC}$. The $\mathrm{Si}(111), 4 \mathrm{H}-\mathrm{SiC}(0001)$ substrates and $\mathrm{GaN}(0001)$ epilayers were chosen given their small lattice mismatches to $\mathrm{ZrB}_{2}$ making them suitable for epitaxial growth.

The films deposited in the industrial system were found to be close to stoichiometric with a low degree of contaminants, with $\mathrm{O}$ being the most abundant at a level of $<1$ at.\%. Furthermore, the structure of the films is temperature dependent as films deposited in this system without external heating are fiber textured with a 0001 -orientation while the films deposited at $550{ }^{\circ} \mathrm{C}$ exhibit random orientation.

In contrast, epitaxial growth was demonstrated in the laboratory scale system on etched $4 \mathrm{H}-\mathrm{SiC}(0001)$ and $\mathrm{Si}(111)$ deposited at $900{ }^{\circ} \mathrm{C}$ following outgassing of the substrates at $300{ }^{\circ} \mathrm{C}$ and in-situ heat treatment at the applied growth temperature to remove the native oxides. However, films grown on $\mathrm{GaN}(0001)$ were found to be 0001 textured at the applied deposition conditions, which make further studies necessary to enable epitaxial growth on this substrate material.

Four point probe measurements on the films deposited in the industrial system show typical resistivity values ranging from $\sim 95$ to $200 \mu \Omega \mathrm{cm}$ with a trend to lower values for the films deposited at higher temperatures and at higher substrate bias voltages. 



\section{Preface}

This licentiate thesis is part of my Ph.D. studies in the Thin Film Physics division at the Department of Physics, Chemistry and Biology at Linköping University. It is a summary of my work between September 2011 and August 2013. Financial support has been provided by the Swedish Research Council (VR). 



\section{Included Papers}

\section{Paper I}

Direct current magnetron sputtered $\mathrm{ZrB}_{2}$ thin films on $4 \mathrm{H}-\mathrm{SiC}(0001)$ and $\mathrm{Si}(100)$

Lina Tengdelius, Mattias Samuelsson, Jens Jensen, Jun Lu, Lars Hultman, Urban Forsberg, Erik Janzén and Hans Högberg

Submitted for publication

\section{Paper II}

Magnetron sputtering of epitaxial $\mathrm{ZrB}_{2}$ thin films on $4 \mathrm{H}-\mathrm{SiC}(0001)$ and $\mathrm{Si}(111)$

Lina Tengdelius, Jens Birch, Jun Lu, Lars Hultman, Urban Forsberg, Erik Janzén and Hans Högberg

Submitted for publication 



\section{Acknowledgements}

Many people have helped me get this far. A few I would like to thank especially:

My supervisor Hans Högberg for giving me the opportunity to work with this project and for pushing me forward. I am also happy to have a chemist ally here in the land of physicists.

My co-supervisor Urban Forsberg and all of my other co-authors for fruitful discussions and for help with performing some of the characterizations.

My officemates David and Olof for nice chats and for always doing your best to answer all the questions I come up with (often computer related).

Everyone in the newly started "Firandegruppen" for serving as a reminder of everything we actually achieve and of course for all the good "fika". Especially thanks to Katarina and Linda.

All the members in Agora Materiae. It is always nice to hang out with you and to get a broader perspective on material research.

Other colleagues in the Thin Film Physics division for contributing to a nice working environment and for sharing good ideas and advice.

All my supporting friends and family. Especially to my mom who is always there for me and who has read everything I have ever written (including this thesis). Also many thanks to Nea for all the tea and listening. You need to move back to Linköping!

My loving husband Mattias for putting up with me. I could never do this without you. 



\section{Contents}

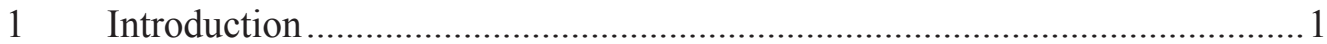

$1.1 \quad$ Aim .

$1.2 \quad$ Outline

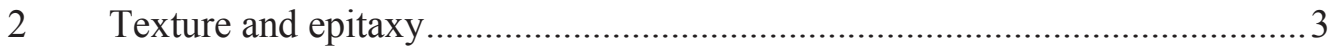

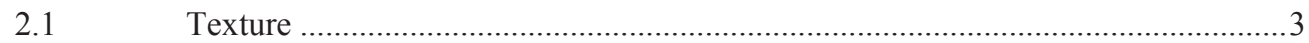

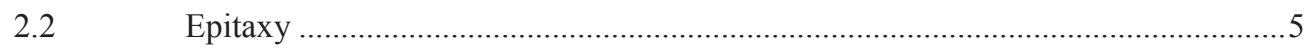

2.2.1 Conditions for epitaxial growth.........................................................................

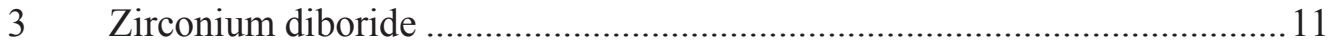

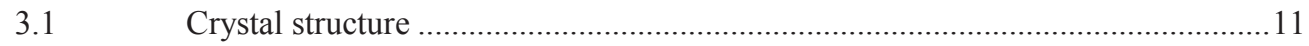

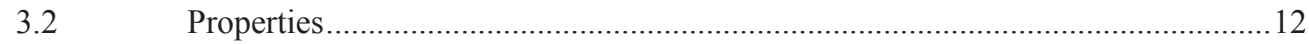

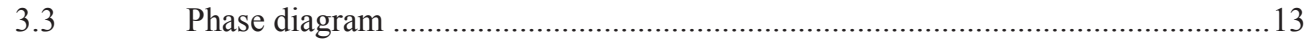

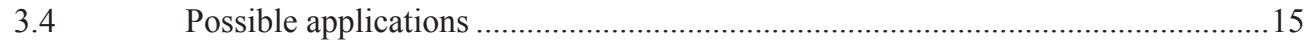

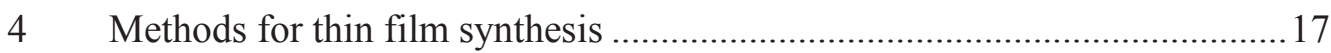

$4.1 \quad$ CVD

4.2 Magnetron sputtering ……………………………………………………....17

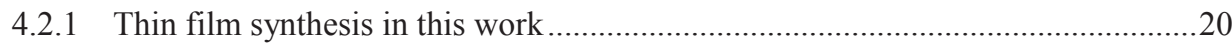

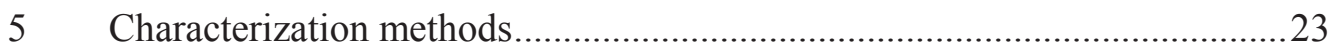

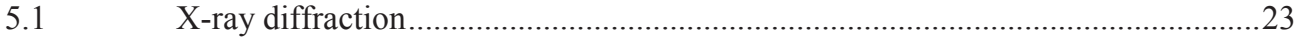

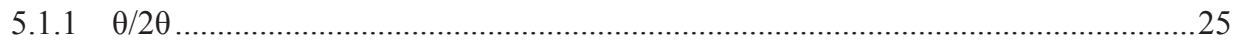

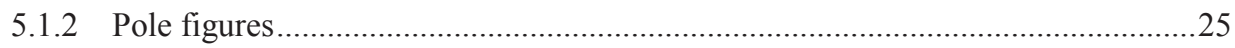

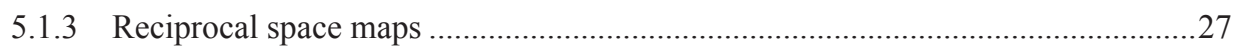

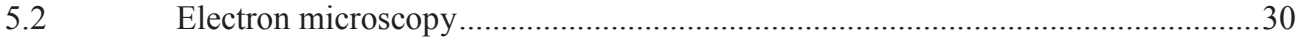




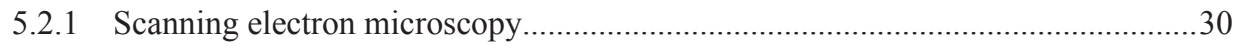

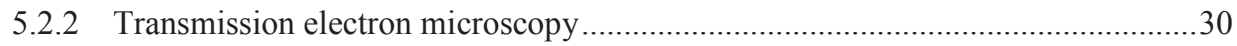

5.2.2.1 Selected area electron diffraction ........................................................ 31

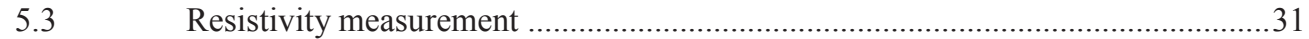

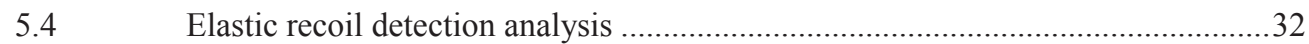

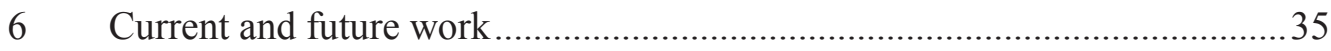

7 Summary of included papers ....................................................... 37

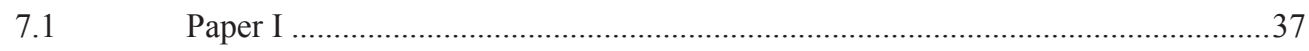

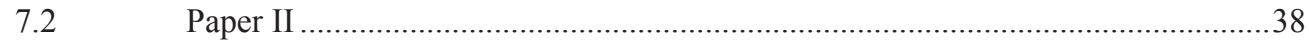

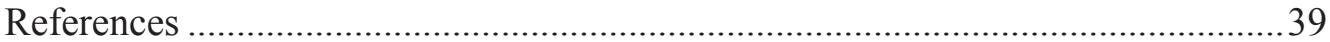




\section{Introduction}

Today thin films are present in one way or another in most people's lives. They can for instance be in the form of anti-reflective coatings on your glasses, non-stick coatings in your frying pan, as protective coatings in food packages or in the microelectronics in your cell-phone or other electronic devices. To coat something with a thin film can greatly alter or enhance the properties of a certain material in order to make it more suitable for a given application. New technologies and products develop every day and with it come demands for new materials with specific properties.

In the development of new thin film materials it is vital to get a thorough understanding of how the films grow and which deposition parameters that will affect the final properties of the film. A lot of fundamental research in thin film physics is focused on enhancing this understanding of thin film growth and there is not always any specific application intended for the final material. This thesis is about the growth and characterization of thin films of zirconium diboride, $\mathrm{ZrB}_{2}$, a ceramic with metallic conductivity that has several potential applications, further described in section 3.4 .

\subsection{Aim}

Several of the imagined applications for $\mathrm{ZrB}_{2}$ thin films require the films to be epitaxial and the aim of this thesis is therefore to deduce the feasibility of growing epitaxial $\mathrm{ZrB}_{2}$ thin films on different technologically important substrates using direct current magnetron sputtering and also to investigate the influence of different deposition parameters on the properties of the films. 


\subsection{Outline}

After this general introduction this thesis will continue with a chapter on texture and epitaxy. Then the structure, properties and possible applications of zirconium diboride will be described. Chapter three describes different vapor based methods to grow thin films and how the synthesis was performed in this thesis. The following chapter will describe the characterization methods used in this work. A summary of the included papers, an outlook towards future work and a list of references will conclude this thesis. 


\section{Texture and epitaxy}

\subsection{Texture}

Texture is the distribution of crystallographic orientations in a polycrystalline sample. If the orientations of the grains are completely random the sample is said to have no texture. This was the case for the films grown at $550{ }^{\circ} \mathrm{C}$ in Paper I. If there is a preferred orientation the sample is textured and the degree of texture is determined by the fraction of grains having the preferred orientation. A sample can be weakly, moderately or strongly textured. In so-called fiber textured samples a certain plane in the deposited crystal is preferentially parallel to the plane of the substrate surface so that by looking at a cross-section of the substrate and film it can be seen that all the grains are aligned in the same way out-of-plane, see Figure 1. However, looking at the film from the top will show that the film is randomly oriented with regards to the in-plane orientation, see Figure 2. The films grown at room temperature in Paper I showed a fiber textured structure, as did the films grown on GaN in Paper II. If on the other hand the film also has a specific orientation in-plane, see Figure 3, the sample is said to have biaxial texture which was the case for the films grown on $4 \mathrm{H}-\mathrm{SiC}(0001)$ and $\mathrm{Si}(111)$ in Paper II . 


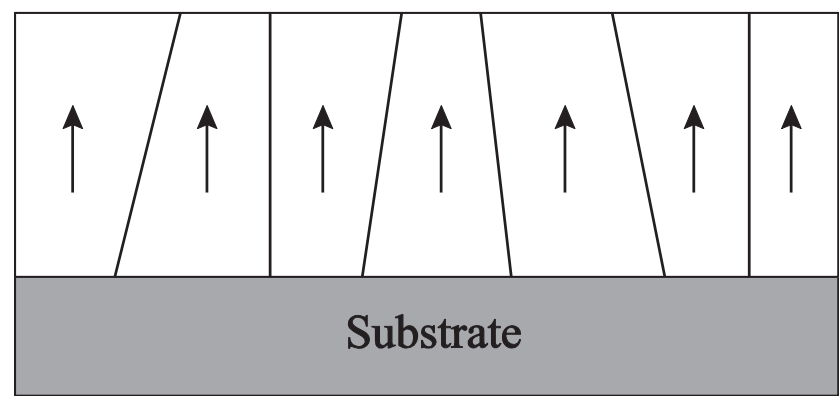

Figure 1 Schematic drawing of a cross-section of a film and substrate showing that all grains are oriented the same way out-of-plane.

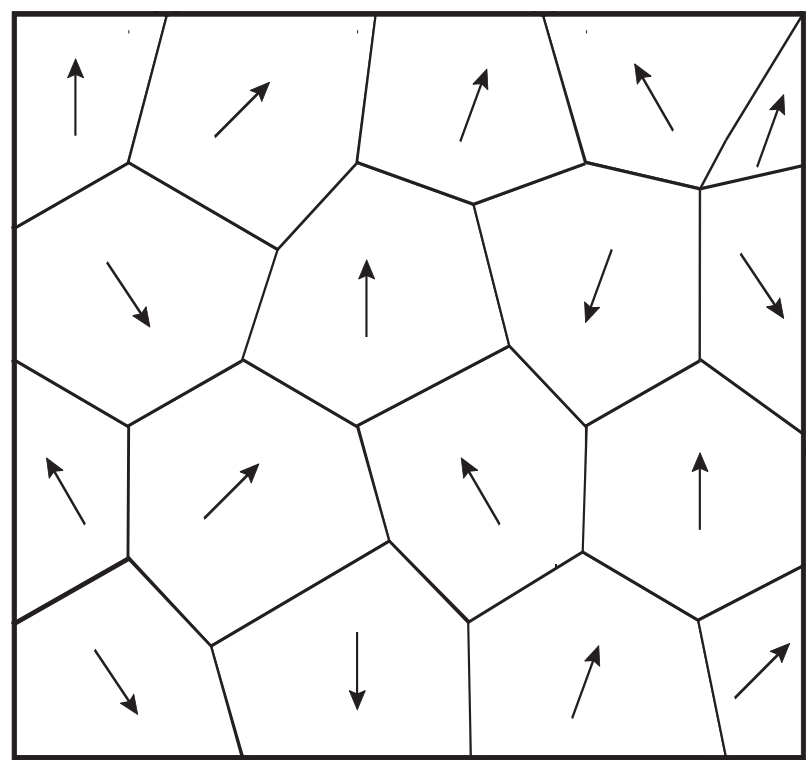

Figure 2 Schematic drawing of a film viewed from above showing that in a fiber-textured film the grains are randomly oriented in-plane. 


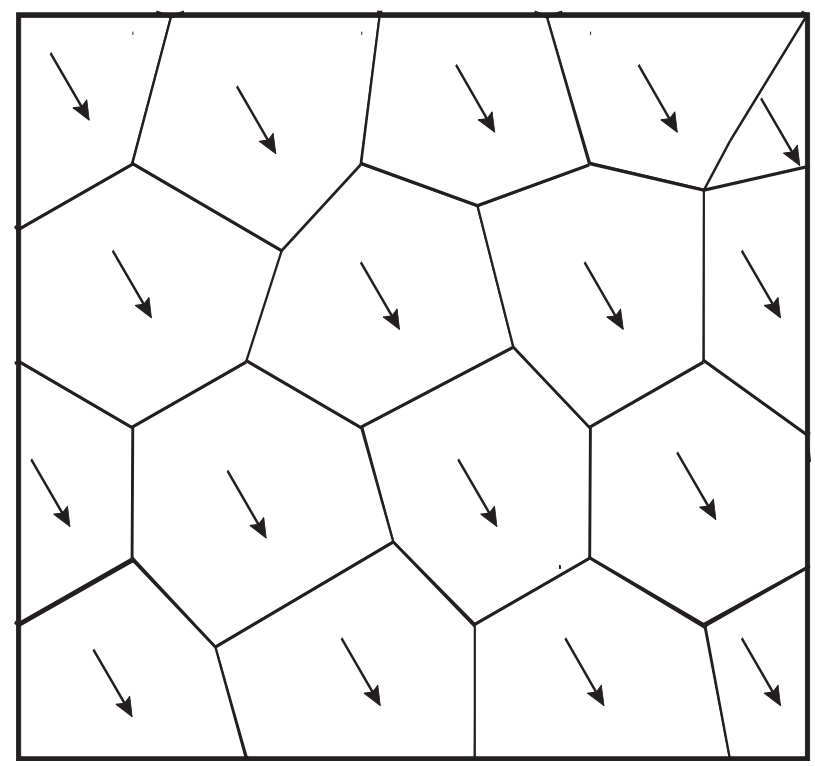

Figure 3 Schematic drawing of a film viewed from above showing that in a biaxial textured film all grains are oriented in the same way in-plane.

\subsection{Epitaxy}

The word epitaxy has its origin in the greek words epi meaning "above" and taxis meaning "in ordered manner". In material science the term refers to the deposition of a layer onto a crystalline substrate were the crystalline orientation of the substrate imposes an order on the orientation of the film. Sometimes the word epitaxy is used to describe all films where there is any relation between film and substrate and sometimes it is used only for single-crystal films. In this thesis, epitaxy will be used to describe a film that exhibits biaxial texture and where the crystallographic axis of the deposited layer is aligned to the axis of the substrate. Growth of such films was achieved in Paper II.

If the film and substrate consists of the same material it is called homoepitaxial growth whereas if the film is of another material than the substrate it is termed heteroepitaxial growth. Homoepitaxial growth is usually used in order to grow films with higher crystal quality, less impurities and/or different doping characteristics than the underlying substrate. Heteroepitaxy is used in order to alter the properties of a given material or when this kind of growth is the only 
alternative in order to achieve a crystal of high quality of the desired material. In this work only heteroepitaxial growth is addressed.

\subsubsection{Conditions for epitaxial growth}

When attempting heteroepitaxial growth one important factor is that the lattice parameters of the film and substrate do not differ too much, otherwise defects due to stress in the film will occur. The misfit parameter, f, can be calculated from the lattice constants, a, according to

$$
f=\frac{a(\text { substrate })-a(\text { film })}{a(\text { substrate })}
$$

- If $\mathrm{f}=0$, i.e. the lattice constant of the film is the same as the lattice constant of the substrate there will be no stresses due to lattice mismatch, see Figure 4. This is the case for homoepitaxial growth.

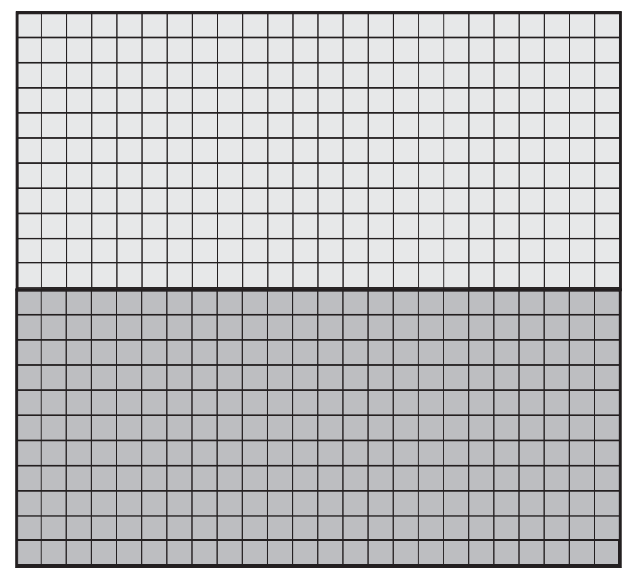

Figure 4 Schematic drawing of a substrate and film with perfect lattice match.

- If $\mathrm{f}<0$, i.e. the lattice constant of the film is larger than the lattice constant of the substrate the film will experience compressive stress in order to match the substrate, see Figure 5. 


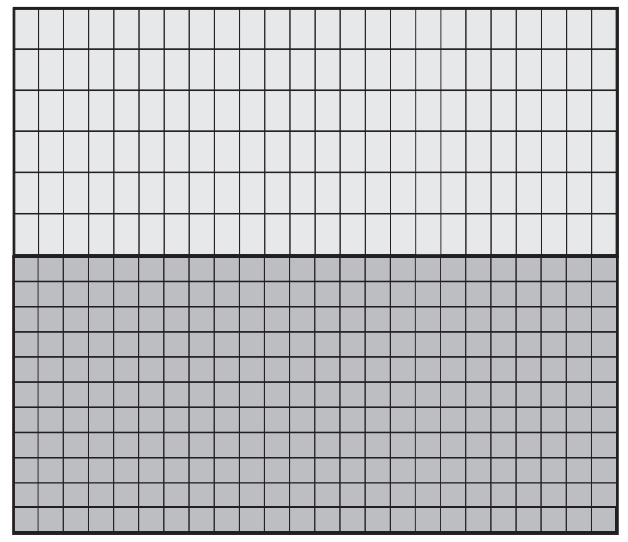

Figure 5 Schematic drawing of a substrate and film where the lattice parameter of the film is larger than that of the substrate causing compressive stress.

- If $\mathrm{f}>0$, i.e. the lattice constant of the film is smaller than the lattice constant of the substrate the film will instead experience tensile stress in order to match the substrate, see Figure 6.

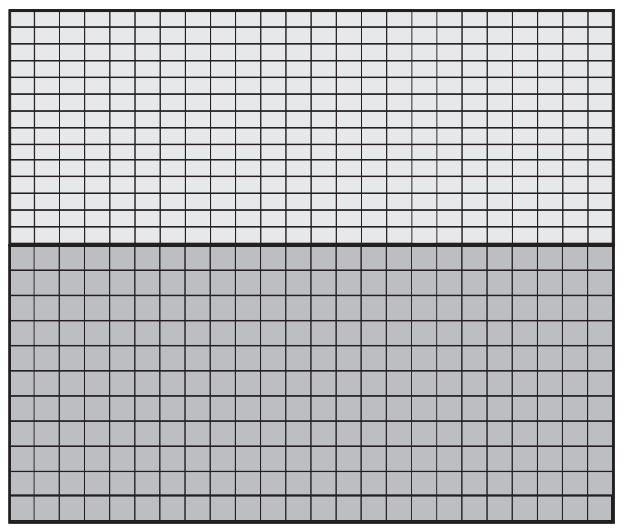

Figure 6 Schematic drawing of a substrate and film where the lattice parameter of the film is smaller than that of the substrate causing tensile stress.

If the mismatch between film and substrate lattice is too large the film will relax which will result in the occurrence of misfit dislocations, see Figure 7. Heteroepitaxial growth is possible when $\mathrm{f} \leq 9 \%$. 


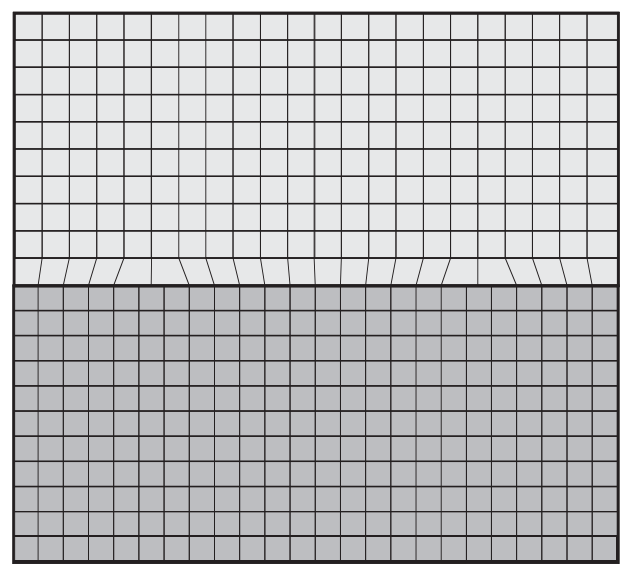

Figure 7 Schematic drawing of a film and substrate where misfit dislocations have occurred due to too high stresses in the film.

Nonetheless, for some substrate/film systems, heteroepitaxial growth has been shown to be possible despite a large mismatch between the film and substrate lattice parameters. This is when a number of unit cells in the film correspond well to another number of unit cells in the substrate, see Figure 8.

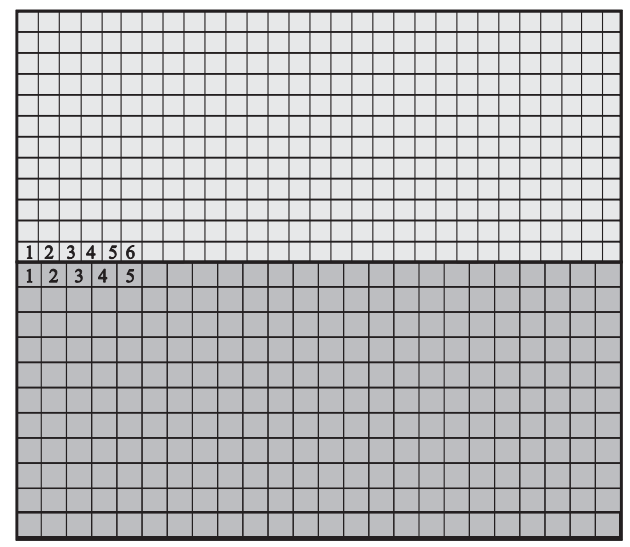

Figure 8 Schematic drawing of a film and substrate that exhibit a magic 6:5 lattice mismatch.

One such example, employed in this work, is $\mathrm{ZrB}_{2}$ on $\mathrm{Si}(111)$ where the misfit is as large as $17.5 \%$ but epitaxial growth is still possible due to a so called 6:5 magic mismatch. However, in this case the distance between $\mathrm{Si}$-atoms in the 111 plane is $3.84 \AA$ and this divided by $3.17 \AA$, the length of 
the $a$-axis of $\mathrm{ZrB}_{2}$, is not exactly $6 / 5=1.2$ but the magic mismatch is still realized by edgedislocations in the form of additional planes inserted into each five $\mathrm{ZrB}_{2}(1 \overline{1} 00)$ layers [1].

When attempting heteroepitaxial growth thermal expansion coefficients of the film and substrate materials also need to be considered since these determine the temperature dependence of their lattice constants. The coefficients for the two materials need to be quite similar so that the effect of temperature on the film and substrate is similar and does not cause the lattice parameter of either the film or substrate to expand considerably more than the other when heated. An example from this work is the attempted heteroepitaxial growth of $\mathrm{ZrB}_{2}$ on $\mathrm{GaN}$ with similar thermal expansion coefficients of $5.9 \cdot 10^{-6} \mathrm{~K}^{-1}$ and $5.6 \cdot 10^{-6} \mathrm{~K}^{-1}$ respectively.

In order for an epitaxial film to be grown the atoms of the deposited material need to be able to find their equilibrium positions. Consequently, the adatoms need sufficient mobility so they do not get "trapped" at a non-optimal position. This is usually achieved by using a high deposition temperature.

For all epitaxial growth, heteroepitaxial as well as homoepitaxial, a high-quality substrate without surface contamination in the form of e.g. native oxide or adventitious carbon is important in order to allow the film to nucleate properly. 



\section{Zirconium diboride}

\subsection{Crystal structure}

Zirconium diboride, $\mathrm{ZrB}$, is a hexagonal material with an $\mathrm{AlB}_{2}$ type structure and its space group is number 191. The boron atoms form honeycombed, graphite-like sheets that are stacked between hexagonal close packed zirconium layers, see Figure 9. The unit cell contains zirconium atoms positioned at the basis $(0,0,0)$ and with boron atoms in the interstitials at $(1 / 3,2 / 3,1 / 2)$ and $(2 / 3,1 / 3,1 / 2)$, see Figure 10. The cell parameters of $\mathrm{ZrB}_{2}$ is $3.17 \AA$ in the $a$ direction and $3.53 \AA$ in the $c$ direction [2]. In Figure 11 the $0001-$ plane of $\mathrm{ZrB}_{2}$ can be seen.

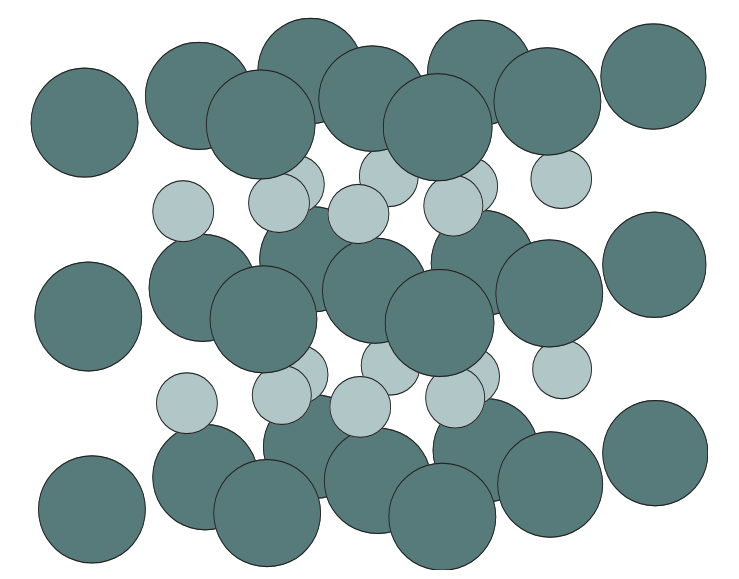

Figure 9 Schematic drawing showing the layered structure of $\mathrm{ZrB}_{2}$. The $\mathrm{Zr}$ atoms are illustrated as dark grey spheres and the B atoms as light grey spheres. 


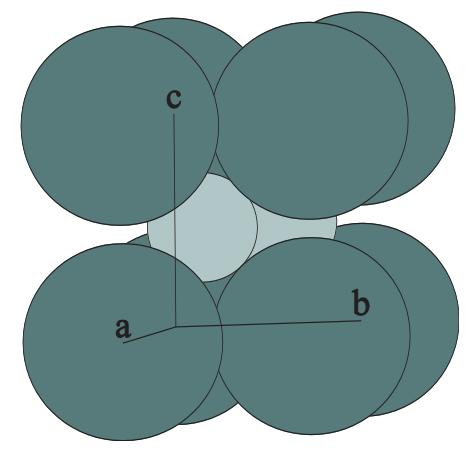

Figure 10 Schematic drawing showing the primitive unit cell of $\mathrm{ZrB}_{2}$ and the crystallographic axes. The $\mathrm{Zr}$ atoms are illustrated as dark grey spheres and the $\mathrm{B}$ atoms as light grey spheres.

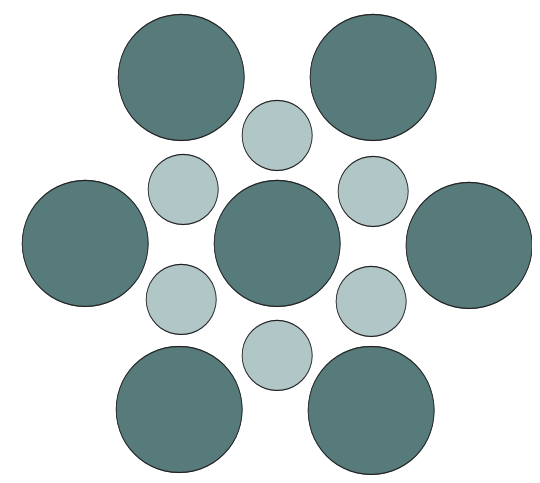

Figure 11 Schematic drawing showing the $\mathrm{ZrB}_{2}$ unit cell seen from the [0001] direction. The $\mathrm{Zr}$ atoms are illustrated as dark grey spheres and the B atoms as light grey spheres.

\subsection{Properties}

$\mathrm{ZrB}_{2}$ exhibit ceramic properties such as high hardness $(23 \mathrm{GPa})$ and high melting point $\left(3245^{\circ} \mathrm{C}\right)$ originating from the covalent type of bonding between the zirconium and boron atoms as well as between the boron atoms in the honeycombed sheet. $\mathrm{ZrB}_{2}$ is also wear and corrosive resistant. In addition $\mathrm{ZrB}_{2}$ has a low resistivity ( $10 \mu \Omega \mathrm{cm}$ in bulk). The electrical conductivity stems from metal-metal bonding and electron transfer from the metal to the boron sheet to yield graphite-like conduction. [2,3] 
A suitable lattice mismatch between film and substrate is, as explained in section 2.2.1, essential to grow epitaxial films. The lattice parameter of $3.17 \AA$ in the $a$ direction gives $\mathrm{ZrB}_{2}$ a small lattice mismatch to technologically important semiconductor-materials such as silicon carbide $(4 \mathrm{H}-\mathrm{SiC}(0001))$ and gallium nitride $(\mathrm{GaN}(0001))$ with values of $-3.8 \%$ and $0.6 \%$ respectively, as well as a magic $6: 5$ mismatch to $\operatorname{Si}(111)$.

\subsection{Phase diagram}

From the phase diagram of $\mathrm{Zr}-\mathrm{B}$ in Figure 12 it can be seen that $\mathrm{ZrB}_{2}$ is a line phase, i.e. it has a very narrow homogeneity range $(<1 \%)$, meaning that the boron to zirconium ratio cannot deviate much from the optimal value of 2. Any excess zirconium or boron atoms will not be accommodated in the structure but instead there will be unwanted phase separation, thus disrupting sought epitaxial growth conditions.

$\mathrm{ZrB}_{2}$ is also highly sensitive to contaminations such as oxygen since the presence of a foreign element during nucleation of $\mathrm{ZrB}_{2}$ will likely cause undesired chemical reactions and possibly hamper the epitaxial growth.

These properties, shown by $\mathrm{ZrB}_{2}$, are in contrast to, e.g., the transition metal carbides and nitrides that are characterized by large homogeneity ranges [4] as well as possible solid solution of oxygen [5]. The phase diagram for $\mathrm{Zr}-\mathrm{C}$ can be seen in Figure 13 where the $\mathrm{ZrC}$ phase is marked as $\gamma$. 


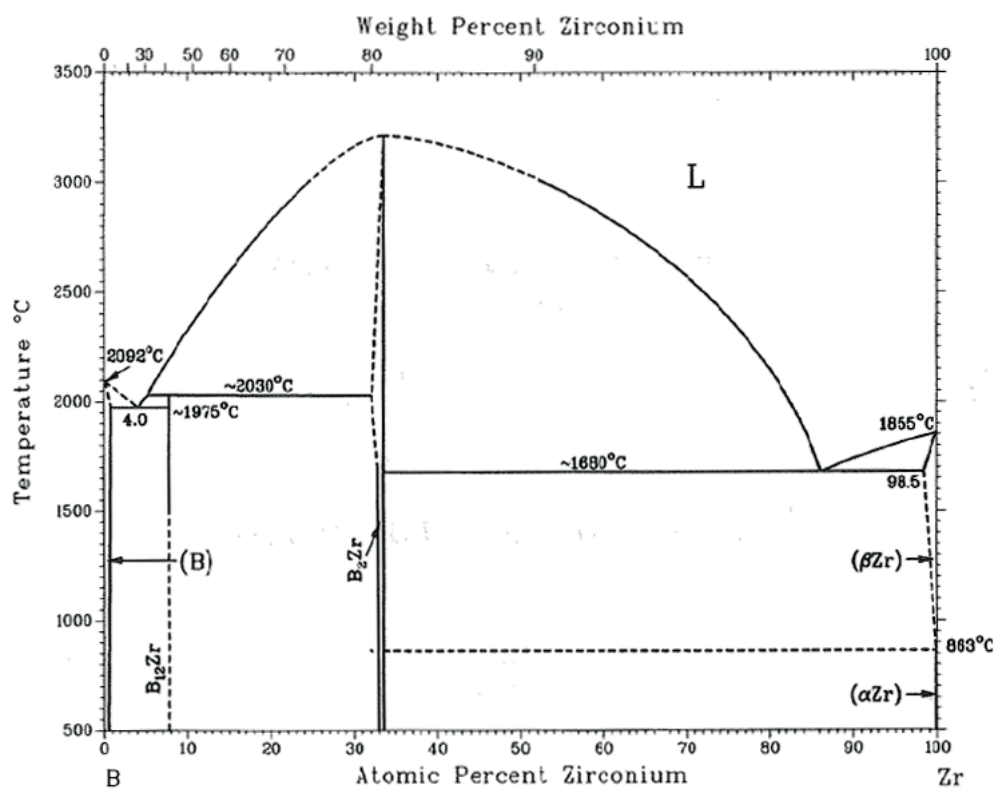

Figure 12 Phase diagram for Zr-B. [6] Reprinted with permission of AMS International. All rights reserved.

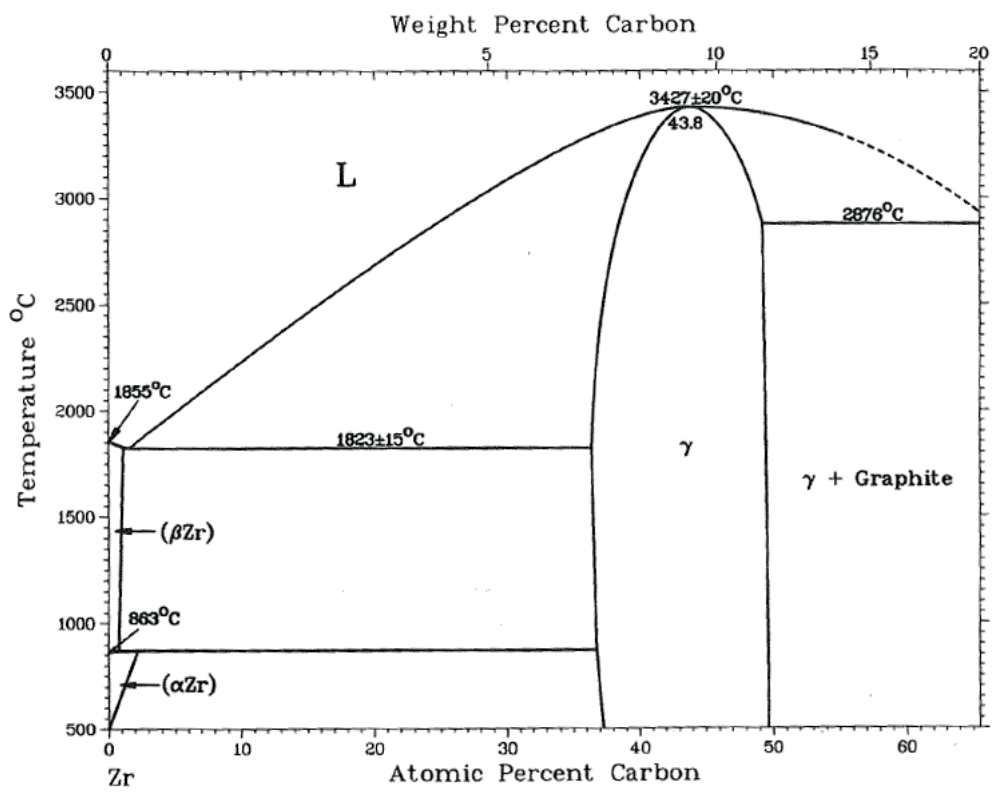

Figure 13 Phase diagram for $\mathrm{Zr}-\mathrm{C}$ where $\gamma$ is the $\mathrm{ZrC}$ phase. [6] Reprinted with permission of AMS International. All rights reserved. 


\subsection{Possible applications}

Although this thesis and the included papers are focused on fundamental research of growth and characterization of $\mathrm{ZrB}_{2}$, I still think it is of importance to mention that there are several possible applications for this material. Three of them will be described below.

$\mathrm{ZrB}_{2}$ has, due to its favorable ceramic properties, a large potential for applications in which conditions of extreme wear, high temperature and/or severe corrosion is present. One such application would be as an electrical contact material at high temperatures. SiC is a very promising material for many high-power and high-temperature electronic device applications. However, one of the major limitations to the full performance of SiC-based devices is the fabrication of Schottky and ohmic contacts. $\mathrm{ZrB}_{2}$ has been suggested as a suitable material for these contacts given its good thermal stability and low resistivity [7]. $\mathrm{ZrB}_{2}$ has also been investigated as contacts on $\mathrm{ZnO}[8]$ and $\mathrm{GaN}[9,10]$.

GaN-based semiconductors are one of the most promising materials for optoelectronic devices such as light-emitting diodes, laser diodes and photo detectors. For the epitaxial growth of GaN the commonly used substrate has been sapphire. However, sapphire has a large lattice mismatch to $\mathrm{GaN}$ of $16 \%$ and the thermal expansion coefficients also differ. The mismatch dislocations produced in $\mathrm{GaN}$ cause serious problems such as crack formation and wafer bending. In some cases it can also be a problem that sapphire is electrically insulating. The small lattice mismatch of $\mathrm{ZrB}_{2}$ and $\mathrm{GaN}$ and their similar thermal expansion coefficients suggest that the use of $\mathrm{ZrB}_{2}$ would lead to a reduction of both dislocation density and biaxial strain in $\mathrm{GaN}$ films and $\mathrm{ZrB}_{2}$ has therefore been proposed as a buffer layer to grow $\mathrm{GaN}$. [11-13] The goal is to deposit $\mathrm{ZrB}_{2}$ on $\mathrm{Si}(111)$ and then grow a layer of $\mathrm{GaN}$ on top, i.e. to merge III-V materials with silicon technology to build cheaper components.

Silicene, the Si counterpart of graphene has been predicted to be stable and have astonishing electronic properties but is difficult to form. Silicene can be easily buckled and may exist with a variety of lattice constants, atomistic structures and $\mathrm{sp}^{2} / \mathrm{sp}^{3}$ ratio. In contrast to graphene, which has a robust crystal structure, silicene is more structurally flexible allowing an engineering of the band structure. The electronic properties of silicene can be modified by epitaxial strain. It has been shown that silicene forms spontaneously by surface segregation of silicon through an epitaxial $\mathrm{ZrB}_{2}$ layer deposited on $\mathrm{Si}(111)$. [14] 



\section{Methods for thin film synthesis}

Vapor-based thin film synthesis techniques are divided into two groups; chemical vapor deposition (CVD) and physical vapor deposition (PVD). PVD includes several methods such as evaporative deposition, pulsed laser deposition, cathodic arc deposition and sputtering. In this work only magnetron sputtering was used. Although CVD is not used in this thesis work, it is still of importance since the method used in Paper II is inspired in part by previously used CVD methods. Therefore brief descriptions of both CVD and magnetron sputtering are included in the following section.

\subsection{CVD}

CVD is a deposition method based on the decomposition and chemical reactions of reactive gaseous species on the substrate surface. The chemical reactions in CVD often require a high substrate temperature. The starting materials in CVD are called precursors and either one single precursor, containing all the elements of the desired film, is used or the different elements are provided from several precursors. It is important that any additional atoms in the precursors that are not of interest for growing the film can form volatile species so that they do not get incorporated in the film. To deposit $\mathrm{ZrB}_{2}$ thin films the single precursor $\mathrm{Zr}\left(\mathrm{BH}_{4}\right)_{4}$ has been used $[1,12,14-18]$. The deposition temperature used was typically $900{ }^{\circ} \mathrm{C}$ and the deposition rate was low $(0.3-1.4 \mathrm{~nm} / \mathrm{min})$.

\subsection{Magnetron sputtering}

Sputtering is a technique where an inert gas is used to eject (sputter) atoms from the target (source material). The inert gas, usually Ar, is ionized by collision with other Ar atoms or with secondary electrons. A negative bias is applied to the target to accelerate the $\mathrm{Ar}^{+}$ions towards it and cause target atoms to be sputtered. The sputtered species are then transported to the substrate 
surface where they condense and form the film. For sputtering to occur, a relatively high Ar pressure must be used but this is unfavorable since the sputtered target atoms are scattered by the Ar species on their way towards the substrate which reduces the growth rate. To reduce this problem the degree of ionization close to the target surface can be enhanced by placing magnets underneath the target to trap electrons in an electric field which is the principle of magnetron sputtering. More $\mathrm{Ar}^{+}$gives a higher sputtering rate which in turn gives a higher growth rate.

Growing a binary compound such as $\mathrm{ZrB}_{2}$ can be done in three ways:

1. By using two targets (co-sputtering), see Figure 14

2. By using one target and one reactive gas (reactive sputtering), see Figure 15

3. By using one target containing both the desired atoms (compound sputtering), see Figure 16

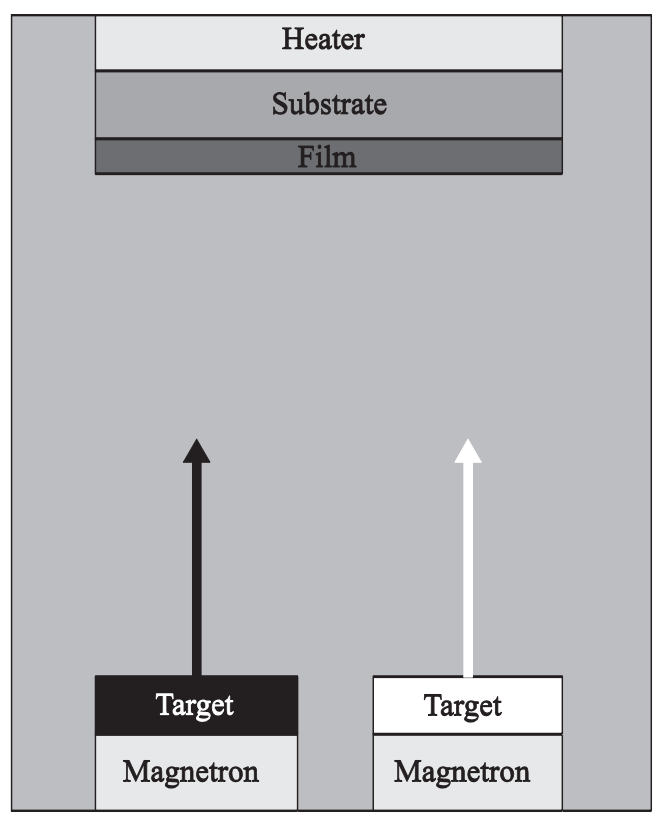

Figure 14 Schematic drawing of the magnetron setup for co-sputtering. 


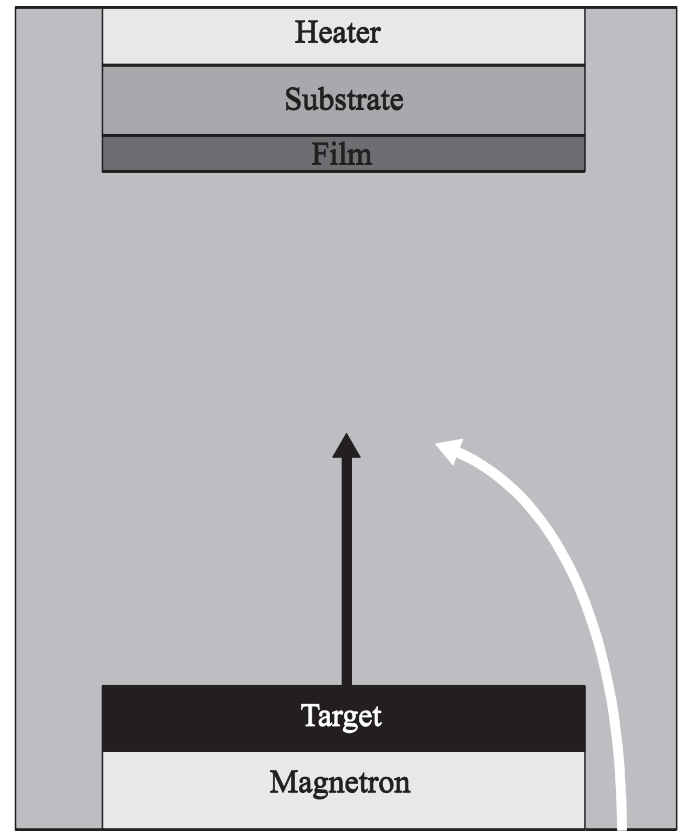

Figure 15 Schematic drawing of the magnetron setup for reactive sputtering.

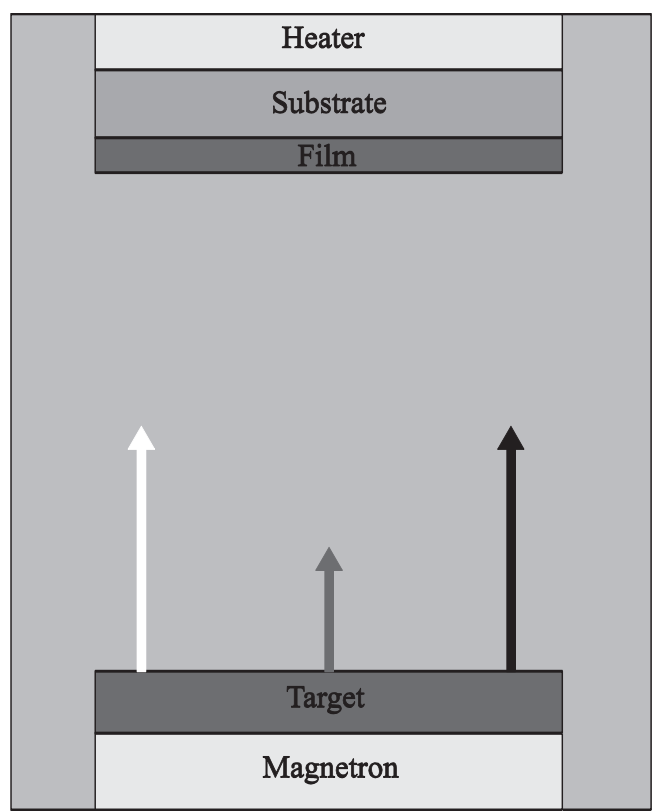

Figure 16 Schematic drawing of the magnetron setup for sputtering from a compound source. 
Reactive sputtering offers the best opportunities to control the amount of each constituent of the film to be deposited since the pressure of the reactive gas can be regulated.

However, reactive sputtering requires a suitable reactive gas to be available. In the case of $\mathrm{ZrB}_{2}$ there is no gas that can serve as the boron source. The most natural candidate diborane, $\mathrm{B}_{2} \mathrm{H}_{6}$, is unfortunately both explosive and highly toxic making it impossible to work with in our available deposition systems. $\mathrm{B}_{2} \mathrm{H}_{6}$ has also been shown to cause substantial target poisoning when depositing the related material $\mathrm{TiB}_{2}$ [19]. The other alternative for sputtering $\mathrm{ZrB}_{2}$ is to use a compound source and that alternative was chosen for this work.

A disadvantage of using a compound target is that the composition of the resulting film is not always the same as the composition of the target due to different energies and angular distribution of the different species. Before reaching a steady state the film will be enriched with the element with the highest sputtering yield. In addition, deviations from stoichiometry can occur due to different sticking probabilities for the elements and composition can also be affected by e.g. growth temperature, substrate bias and what substrate material is used. Furthermore, atoms from the film surface can be re-sputtered and the probability for this is higher for light elements compared to heavier elements.

The magnetron sputtering technique used in the included papers in this thesis is direct current magnetron sputtering, DCMS. In DCMS a constant power is applied to the target. In Paper II the power density of the target was $8.77 \mathrm{~W} / \mathrm{cm}^{2}$ and the resulting current density was $20 \mathrm{~mA} / \mathrm{cm}^{2}$. DCMS results in a low degree of ionization of the sputtered material (less than $10 \%$ for metals) which means that the majority of the sputtered flux is neutral and low in energy [20]. To increase ionization and therefore the deposition rate higher power densities need to be applied to the target. However, this can only be done to a certain point or the target will be overheated. Another alternative to increase ionization is to use pulsed deposition techniques where high powers are applied to the target in short pulses followed by time for the target to cool down but no such technique is used in this work.

\subsubsection{Thin film synthesis in this work}

All films in this work were grown using direct current magnetron sputtering from compound sources. 
In Paper I the influence of temperature and substrate bias voltage on the composition, structure and resistivity of the films was investigated.

When applying a substrate bias voltage the energy and flux of the incident particles are modified due to an alteration of the electric fields near the substrate. Several of the properties of the film may be affected by a bias voltage including film morphology, density, grain size, preferred orientation, adhesion to the substrate, residual stresses in the film and composition [21]. When the film surface is bombarded by energetic particles the surface mobility of adatoms is elevated. Consequently, applying a substrate bias voltage is a way to achieve sufficient adatom mobility for epitaxial growth.

In Paper I it was seen that an increased bias voltage increased the residual stresses in the films. Also, an increased bias voltage combined with a higher temperature affected the composition of the films and made them enriched with zirconium.

As discussed in section 3.3, a stoichiometric flux is paramount when growing $\mathrm{ZrB}_{2}$ thin films to avoid phase separation. A low level of contaminants especially oxygen is important in order not to degrade the electronic properties of the films [22]. The literature shows that films with composition deviating, sometimes substantially, from the ideal value have been deposited when sputtering from a compound source. Also, results on films with a high level of contaminants, including oxygen values of as high as $30 \%$, have been reported. [7-9,22-27] One of the purposes for Paper I was therefore to investigate whether it was possible to grow stoichiometric films with a low degree of impurities even using a compound source and a high vacuum industrial scale system. In order to minimize the effect of the residual gas, chemical getter pumping by titanium was applied as well as high deposition rates and short deposition times (100 s) at a high power density of the target $\left(11.36 \mathrm{~W} / \mathrm{cm}^{2}\right)$. The results showed that it was possible to grow stoichiometric films under these circumstances, albeit with the already mentioned exception that a combination of a temperature of $550{ }^{\circ} \mathrm{C}$ and a substrate bias voltage of $-80 \mathrm{~V}$ resulted in boron depleted films with a $\mathrm{B} / \mathrm{Zr}$ ratio of about 1.8. The level of contamination was low in all films with typical values below 0.2 at.\% for $\mathrm{H}, \mathrm{Ar}$, and $\mathrm{N}$ and 0.4 at.\% for $\mathrm{C}$ and 1 at.\% for $\mathrm{O}$. The oxygen level was slightly higher in the films grown without additional heating and oxygen profiles showed that the oxygen content was higher at the film/substrate interface. Transmission electron microscopy (TEM) micrographs showed that there was an amorphous/nanocrystalline layer at the 
interface of these films whereas such a layer was not present in the films grown at higher temperature. An amorphous layer is detrimental when trying to achieve epitaxial growth so these results indicated that the films need to be deposited at a high enough temperature to avoid the growth of such a layer. Since the oxygen level was higher at this interface and part of that could be due to the native oxide layer always formed on the substrate surface we also concluded that thorough cleaning of the substrates was essential in order to achieve epitaxial growth.

The observations from this first study and influences from some earlier studies using CVD $[1,12,14,16,17]$ inspired the study which was the base for Paper II. In this second study an ultra-high vacuum system was used, the substrates were cleaned thoroughly including an etching step with hydrofluoric acid and outgassed in the load-lock of the system. The reasons for choosing a deposition temperature of $900{ }^{\circ} \mathrm{C}$ were: 1) In Paper I the films exhibited fiber texture when deposited at room temperature and a random orientation when grown at $550{ }^{\circ} \mathrm{C}$, indicating that these temperatures are not sufficient to get enough adatom mobility in order to grow an epitaxial film, see section 2.2.1, and 2) all epitaxial CVD films have more or less exclusively been grown at $900{ }^{\circ} \mathrm{C}$. X-ray diffraction and TEM showed that our films grown on $4 \mathrm{H}-\mathrm{SiC}(0001)$ and $\mathrm{Si}(111)$ grew as epitaxial columns while the film on $\mathrm{GaN}(0001)$ was fiber-textured. 


\section{Characterization methods}

\subsection{X-ray diffraction}

$\mathrm{X}$-ray diffraction (XRD) is one of the most used characterization techniques in material science. The reason that $\mathrm{x}$-rays are used is that their wavelength is in the order of the distance between planes in a crystal. When a crystal is irradiated with x-rays, some of the x-rays are elastically scattered by the core electrons of the atoms in the sample and constructive interference occur according to Bragg's law

$$
n \lambda=2 d_{h k l} \sin \theta
$$

where $\mathrm{n}$ is an integer, $\lambda$ the wavelength of the $\mathrm{x}$-rays, $\mathrm{d}_{\mathrm{hk} 1}$ the distance between lattice planes with Miller indices $\mathrm{hkl}$ and $\theta$ the diffraction angle. In other words the minimum requirement for constructive interference to occur is that the path difference between the diffracted beams needs to be an integer of the wavelength of the x-rays used. Bragg's law is visualized in Figure 17.

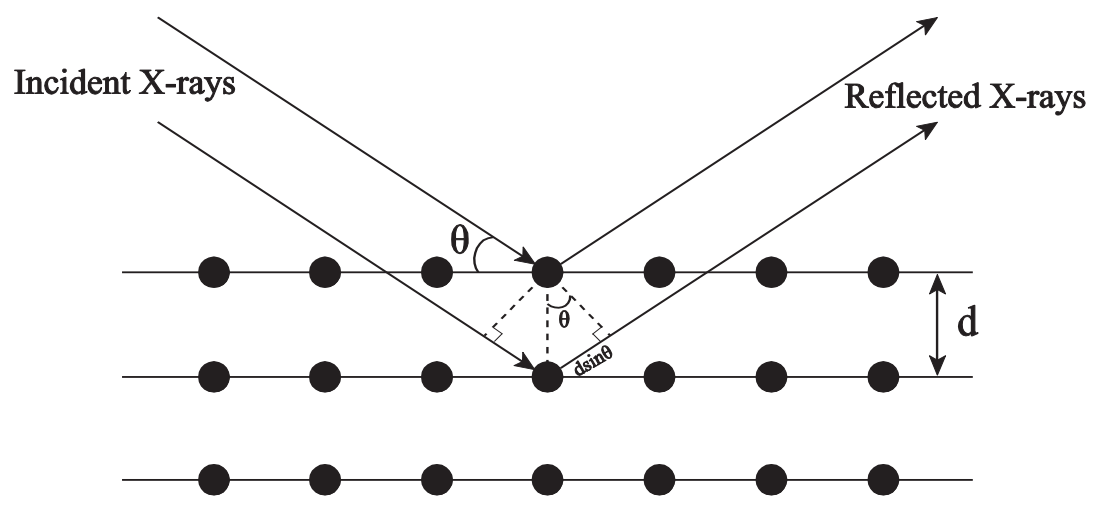

Figure 17 Schematic illustration of Bragg's law. 
However, not all hkl that satisfies Bragg's law will give a reflection peak; the allowed reflections are determined by the structure factor which in turn is determined by the crystal structure. The position of the peaks in a diffractogram is dependent on which atoms are present in the crystal and where they are located, giving each material its own "fingerprint" diffractogram. Thus, XRD can be used to confirm the identity of a material. However, usually this is not all you want to know about your material and XRD can also provide information on the orientation of the film, the crystal quality and the lattice parameters among other things. To measure these properties several methods are used, the three used in this thesis are described below. The notation of angles used in these methods is shown in Figure 18.

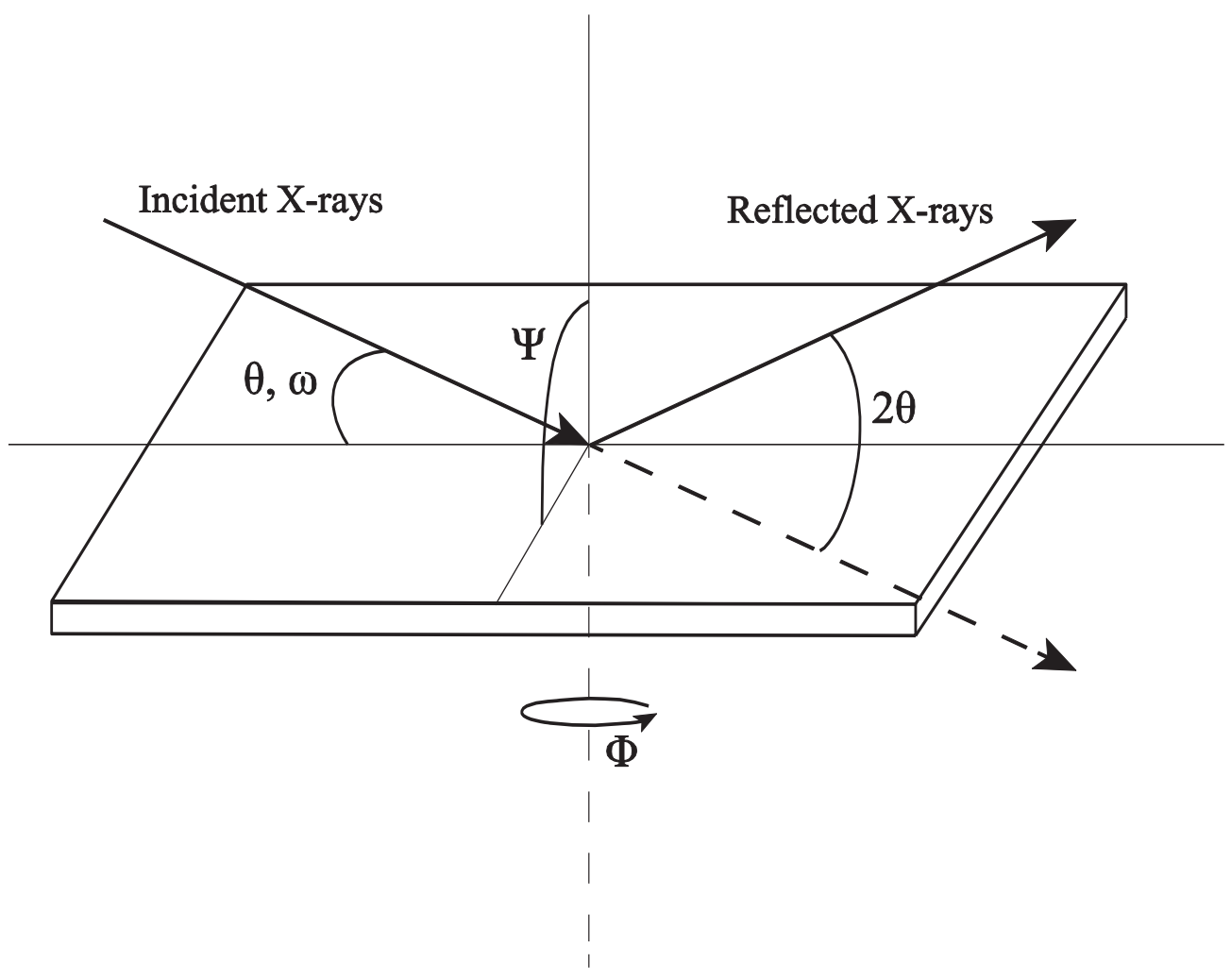

Figure 18 Notation of the angles used in XRD. 


\section{$5.1 .1 \theta / 2 \theta$}

In a $\theta / 2 \theta$ scan the incident and reflected angle are always the same and both are changed simultaneously, thus $\theta / 2 \theta$ is a symmetrical scan. This means that only the crystal planes parallel to the sample surface will be seen in the diffraction pattern. For a totally randomly oriented powder sample all planes will at some point be parallel to the surface and all allowed diffraction peaks will be seen. In thin films it is common that some growth directions are more favorable than others and not all planes will have the same probability of being parallel to the surface. In Figure 19 an example of a diffractogram where three films grown at different temperatures and oriented in different ways can be seen. If the intensity of one diffraction peak compared to the others is much higher it is likely that the film is either textured or epitaxial. To determine which it is, pole figure measurement can be performed.

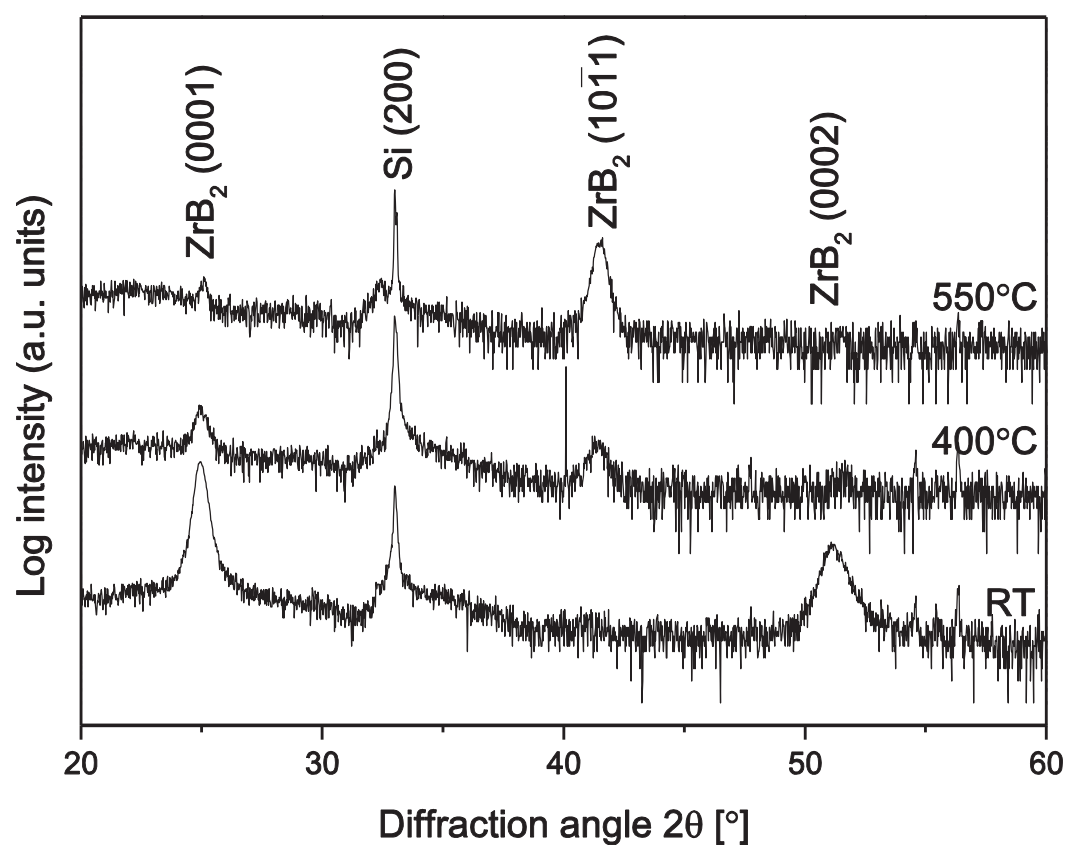

Figure 19 Diffractograms of three $\mathrm{ZrB}_{2}$ films grown on $\mathrm{Si}(100)$ at different temperatures exhibiting different preferred orientations.

\subsubsection{Pole figures}

In a pole figure the diffracted beam is fixed at one particular $\theta / 2 \theta$-value, corresponding to the plane that is being investigated. The sample is then tilted in the $\Psi$ direction and rotated in the $\varphi$ 
direction and the detected intensity is plotted as a stereographic projection. The angles used in this work were $0 \leq \Psi \leq 85$ and $5 \leq \varphi \leq 360$.

A randomly oriented film will show uniform intensity, see Figure 20. For a textured sample where the grains are oriented in the same way in one direction but randomly in the plane there will be diffraction at a certain $\Psi$ and for all values of $\varphi$, resulting in a pattern seen in Figure 21. If the film is epitaxial and all grains are oriented the same in all directions, diffraction will occur only at certain values of $\Psi$ and $\varphi$ resulting in a pattern of distinct spots as seen in Figure 22. The number of spots and the distance between them is determined by the symmetry of the investigated plane. The $\Psi$-value corresponds to the angle between the investigated plane and the planes parallel to the surface of the sample.

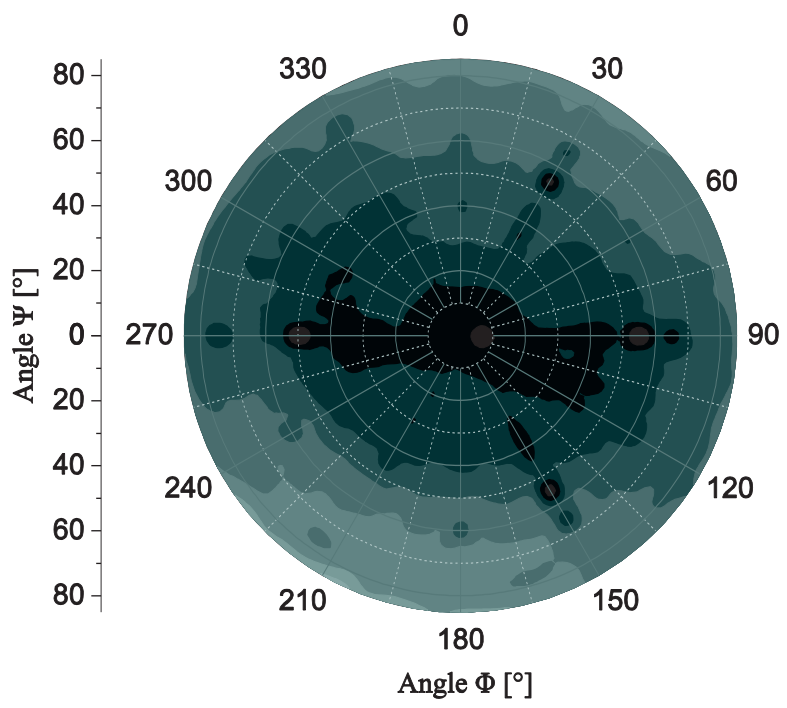

Figure 20 Pole figure of the $10 \overline{1} 1$ pole of a $\mathrm{ZrB}_{2}$ film grown on $4 \mathrm{H}-\mathrm{SiC}(0001)$ at $550{ }^{\circ} \mathrm{C}$. 


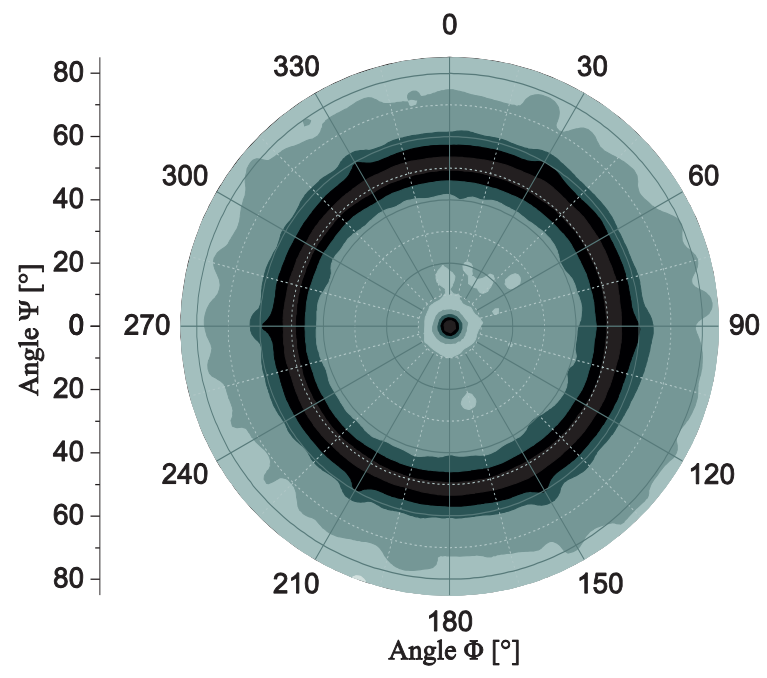

Figure 21 Pole figure of the $10 \overline{1} 1$ pole of a $\mathrm{ZrB}_{2}$ film grown on $\mathrm{GaN}(0001)$ at $900{ }^{\circ} \mathrm{C}$.

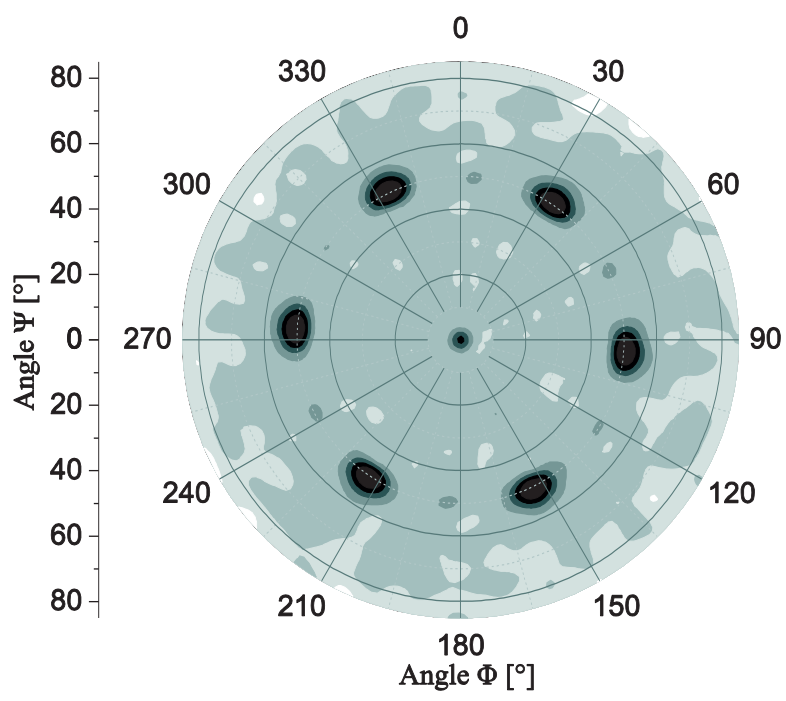

Figure 22 Pole figure of the $10 \overline{1} 1$ pole of a $\mathrm{ZrB}_{2}$ film grown on $4 \mathrm{H}-\mathrm{SiC}(0001)$ at $900{ }^{\circ} \mathrm{C}$.

\subsubsection{Reciprocal space maps}

Reciprocal space maps (RSMs) can be recorded to investigate a certain lattice point in reciprocal space. The shape and position of the reciprocal lattice point gives information about the in-plane 
and out-of-plane lattice parameters, crystal quality, strain, relaxation and mosaicity of the films. [28]

Reciprocal space maps (RSMs) in Paper II were collected by performing consecutive coupled $2 \theta-\omega$ measurements, each with a small difference in $\omega$-value, see Figure 23 . This means that the reflection is not only monitored by one measurement crossing it, but the whole area in the vicinity of the reflection is included in the measurement. For each sample one symmetric and one asymmetric Bragg reflection was investigated.

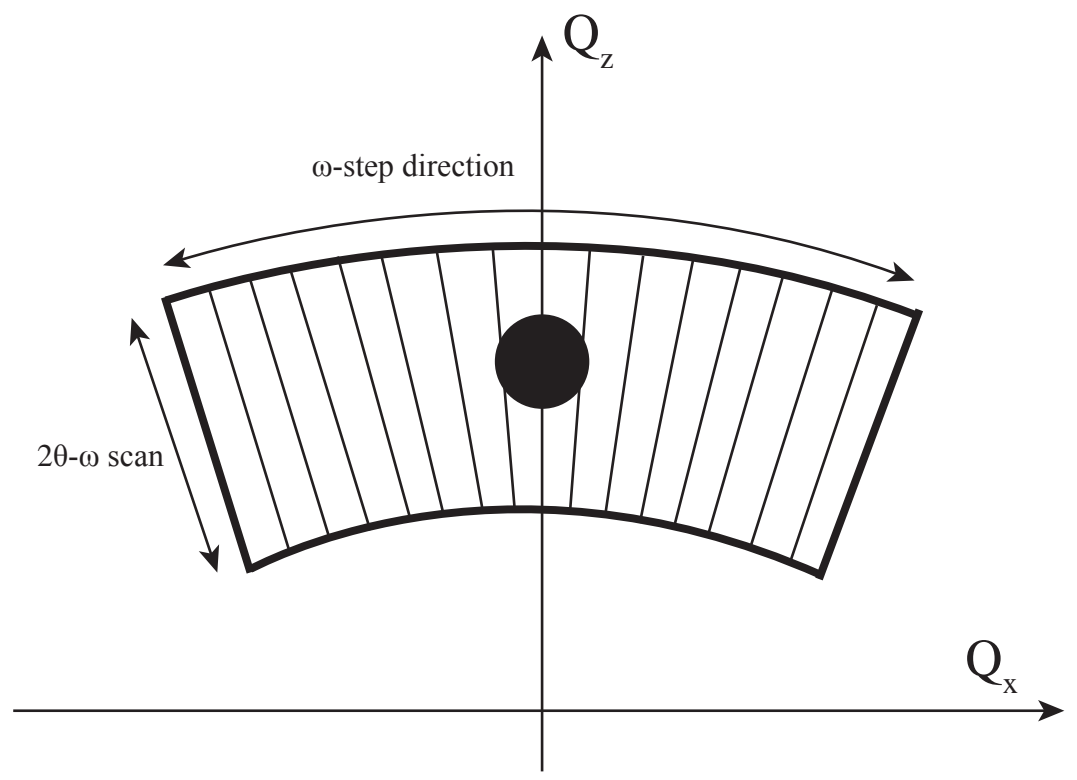

Figure 23 Schematic drawing of how a reciprocal space map is recorded by consecutive coupled $2 \theta-\omega$ scans.

RSMs are plotted as diffraction intensity contours in the reciprocal space coordination system where $\mathrm{Q}_{\mathrm{z}}$ is the out-of-plane component and $\mathrm{Q}_{\mathrm{x}}$ the in-plane component. An example from Paper II, for one symmetric and one asymmetric reflection can be seen in Figure 24 and Figure 25 respectively. 


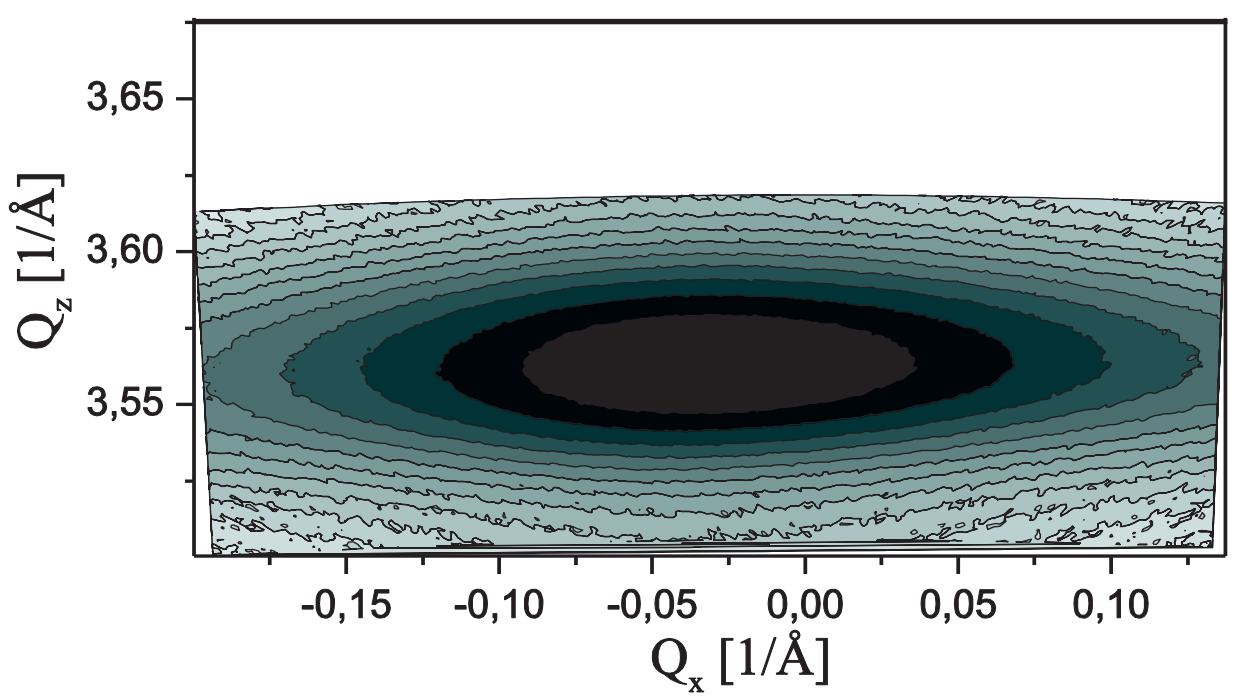

Figure $24 \mathrm{RSM}$ of the $\mathrm{ZrB}_{2} 0002$ lattice point recorded for a film grown on $\mathrm{Si}(111)$.

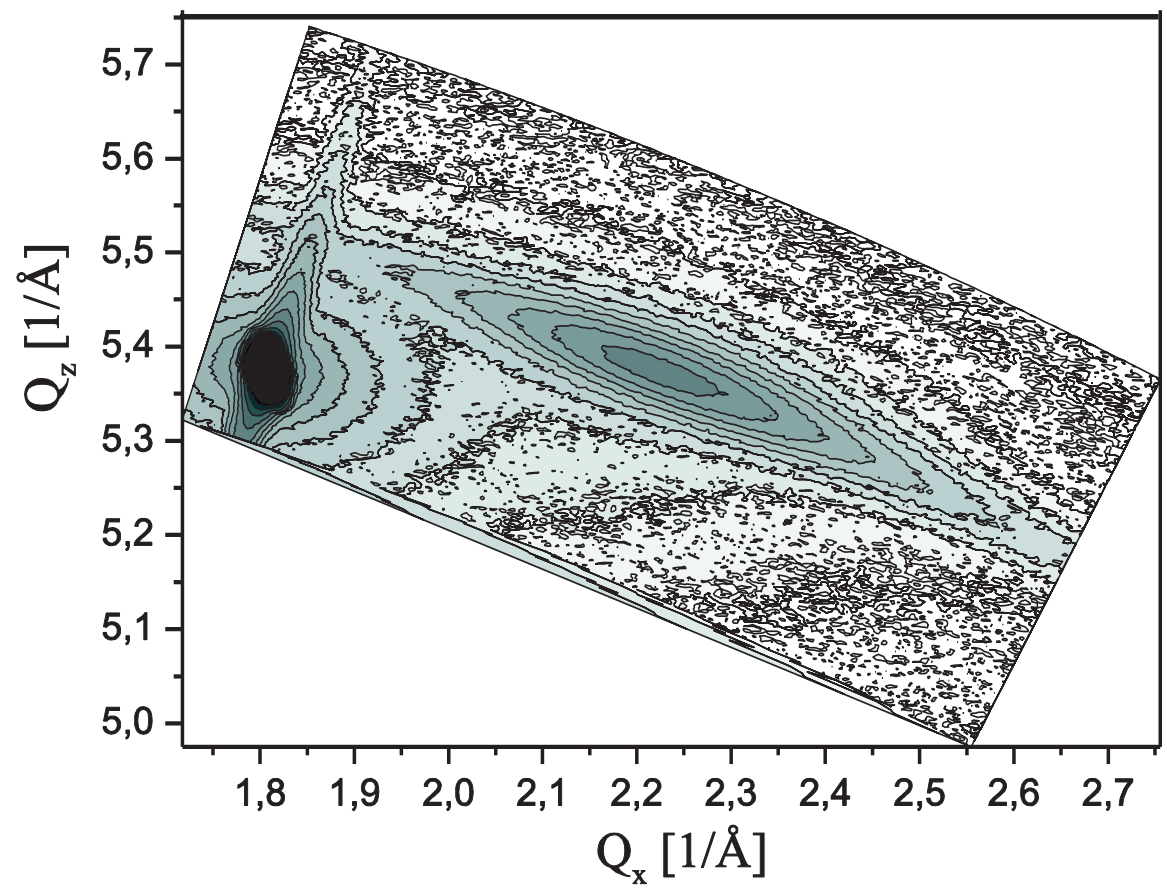

Figure $25 \mathrm{RSM}$ of the $\mathrm{ZrB}_{2} 10 \overline{1} 3$ lattice point recorded for a film grown on $\mathrm{Si}(111)$. In the lower left corner the 313 lattice point from the substrate is also seen. 


\subsection{Electron microscopy}

In the electron microscope (EM) a beam of electrons are used to illuminate the sample in the same way as the source of visible light in a light optical microscope (LOM). The beam is focused and the image generated with the help of electromagnetic lenses equivalent to the glass lenses in the LOM. The biggest advantage of the EM, compared to the LOM, is the improved resolution stemming from the smaller wavelength of electrons in comparison to visible light. However, whereas glass lenses have been perfected for a long time electromagnetic lenses are still of rather bad quality and limits the resolution attained. The best EMs can achieve a magnification of $50000000 \mathrm{x}$ and a resolution in the order of $50 \mathrm{pm}$ while the best LOMs are limited to a magnification of about 2000x and a resolution of $200 \mathrm{~nm}$ [29].

\subsubsection{Scanning electron microscopy}

In scanning electron microscopy (SEM) the electron beam is scanned over the surface of a sample. The electrons in the beam is accelerated to a voltage of $\sim 1-60 \mathrm{keV}$ and interact with the atoms in the sample which causes secondary electrons, backscattered electrons, Auger electrons, $\mathrm{X}$-rays and light to be emitted from the sample. The image is generated by displaying the intensity for the selected signal for each position of the beam while it scans the sample. Secondary electrons have a short mean free path following their low energy and therefore originate from the surface of the sample making them ideal for topographic imaging of the sample surface. The resolution of a SEM is $\sim 2 \mathrm{~nm}$, about an order of magnitude larger than for transmission electron microscopes described below. However, the SEM has other advantages including that it is a non-destructive method, requires minimal or no sample preparation and has a large depth of field making it easy to interpret an image from a 3D-shaped object.

In this work, SEM was used to investigate the morphology of the cross-sectional films and also to measure the thicknesses of the films. The obtained thicknesses were then used to calculate the deposition rate of the films by dividing the thickness with the deposition time and also to calculate the resistivity of the films (see below).

\subsubsection{Transmission electron microscopy}

In transmitted electron microscopy (TEM) the electrons are accelerated to a voltage of $\sim 200 \mathrm{keV}$ and then either transmitted through or scattered from the sample. This results in different 
intensities of the transmitted beam holding information of the structure of the sample. TEM requires the sample to be very thin, preferably less than $50 \mathrm{~nm}$ thick, and the sample preparation is therefore complicated and time-consuming as well as destructive. This and the fact that it can be difficult to interpret the results are the main disadvantages of the TEM. The main advantages are the high spatial resolution and the possibility to get information from both real (imaging) and reciprocal (electron diffraction) space.

There are a number of ways to generate contrast in a TEM image. The most common way is called bright field where an aperture in the back focal plane of the objective lens is used to block the scattered electrons and the image is constructed based on the intensity of the transmitted beam. Areas of the sample which diffract more are imaged as darker than the areas that permit more electrons to be transmitted through the sample. To use dark field, the aperture in the back focal plane of the objective lens is used to block the transmitted beam instead and the scattered electrons are used for imaging. In dark field images the areas that diffract more will be displayed as bright. In high resolution transmission electron microscopy (HRTEM) phase contrast is utilized. Both the transmitted and scattered beams are used and the path difference of the two beams gives rise to interference and thus generates contrast in the image. With HRTEM it is possible to get lattice resolved images.

\subsubsection{Selected area electron diffraction}

In a TEM a diffraction pattern is formed in the back focal plane of the objective lens when the electron beam is diffracted by the atoms in the sample and Bragg's law is fulfilled in a similar way as in XRD. By changing the strength of the intermediate lens this diffraction pattern can be imaged instead of the ordinary image. An aperture inserted in the image plane of the objective lens makes it possible to choose a beam from a very limited part of the sample, so called selected area electron diffraction (SAED) and thus obtain crystallographic information from just one grain or another very small area of interest.

\subsection{Resistivity measurement}

The resistivity of a thin film can be measured with a four-point probe. Figure 26 shows a schematic drawing of a four point probe pressed against the surface of a thin film. 


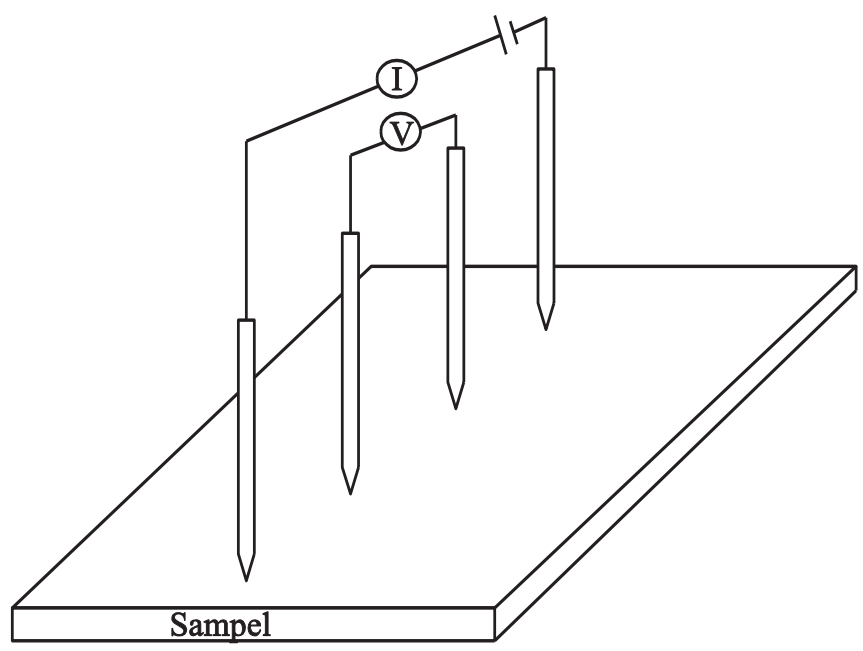

Figure 26 Schematic drawing of the set-up for a four-point probe.

One pair of the probe measures the current and the other pair the voltage. From this the sheet resistance $R_{s}$ of a thin sheet can be obtained from

$$
R_{S}=\frac{\pi}{\ln 2} \frac{V}{I}=4.532 \frac{V}{I}
$$

where $\mathrm{I}$ is an applied current and $\mathrm{V}$ is the measured voltage. This equation is valid for $\mathrm{t} \leq \mathrm{s} / 2$ where $t$ is the thickness of the film and $s$ is the distance between probes. For the instrument used in this work the sheet resistance $\mathrm{R}_{\mathrm{s}}$ is obtained from the instrument directly. The sheet resistance is then multiplied with the film thickness (obtained from SEM) in $\mathrm{cm}$ to get the specific resistivity ( $\rho$ ) of the film in $\Omega \mathrm{cm}$ according to

$$
\rho=R_{s} \times t
$$

\subsection{Elastic recoil detection analysis}

Elastic recoil detection analysis (ERDA) is a quantitative as well as qualitative ion beam technique used to analyze the chemical composition and level of contaminants in a film. A beam of heavy ions with high energy is used to "kick out" or recoil atoms from the film in the forward direction. In this work the measurements were carried out using a $36 \mathrm{MeV}^{127} \mathrm{I}^{8+}$ ion beam and the 
incident angle was such that the recoil angle was $45^{\circ}$. The energy of the ejected atoms is measured and since the collision is assumed to be fully elastic the mass of the target atom can be calculated from the kinematic factor $\mathrm{k}_{\mathrm{ER}}$ according to

$$
k_{E R}=\frac{E_{R}}{E_{p}}=\frac{4 M_{P} \times M_{R}}{\left(M_{P}+M_{R}\right)^{2}} \cos ^{2} \theta
$$

where $E_{P}$ and $M_{P}$ is the energy and mass of the projected ion respectively, $E_{R}$ and $M_{R}$ is the energy and mass of the recoiled atom and $\theta$ is the recoil angle. The energy of the ejected atoms is also dependent on the depth of their origin in the film. In this work time-of-flight ERDA was used where, in addition to the energy of the atoms, their velocity is also measured to be able to determine both the mass of the ejected atoms but also enabling depth profiles of the elements in the film. This was utilized in Paper I and enabled us to see that the oxygen content in the films were higher at the film-substrate interface compared to the bulk of the film.

ERDA is best suitable for light elements and an advantage compared to many other techniques is the possibility to measure hydrogen. Disadvantages are that you need access to a tandem accelerator and that the evaluation of data is not trivial. 



\section{Current and future work}

The films and results presented in Paper II is a subpart of a larger deposition series aimed at further investigating the influence of temperature, as well as the effect of power density applied on the target, on the properties of the films. At present I am working on further characterizing the films and analyzing the results from this growth study. Later I would also like to test if increased power density of the target could make it possible to deposit epitaxial films at lower temperatures.

Further on, annealing of the as-deposited films will be performed to investigate the effect on the electronic properties of the films.

Also, the reasons why we do not get epitaxial growth when depositing on GaN substrates will be further investigated.

Depending on the outcome of these experiments I will either try to enhance the properties of the deposited films by trying alternative deposition methods or if the films are of satisfactory quality start a collaboration to begin building electronic components. 



\section{Summary of included papers}

\subsection{Paper I}

In this paper $\mathrm{ZrB}_{2}$ thin films was deposited on $4 \mathrm{H}-\mathrm{SiC}(0001)$ and $\mathrm{Si}(100)$ substrates by direct current magnetron sputtering of a compound target in an industrial scale high vacuum system. The influence of temperature and substrate bias voltage on the composition, structure and resistivity of the films was investigated.

The results showed that stoichiometric films can be grown but also that the combination of an elevated temperature of $550{ }^{\circ} \mathrm{C}$ and a substrate bias of $-80 \mathrm{~V}$ resulted in boron depleted films with a $\mathrm{B} / \mathrm{Zr}$ ratio of about 1.8 . Only increased temperature or bias voltage was in itself not sufficient to alter the composition. The amount of contaminants, especially the oxygen level, in the films was determined to be low compared to other PVD films.

The orientation of the films was also shown to be influenced by temperature; $\theta / 2 \theta$ scans determined the films deposited at RT to be 0001 oriented while the films deposited at higher temperature were randomly oriented. Pole figure measurements showed that the 0001 oriented films were fiber textured.

TEM investigation revealed that there was a nanocrystalline or amorphous layer at the film-substrate interface in the film deposited at RT while such a layer was not present in films grown at an elevated temperature. Since such a layer is likely to hamper epitaxial growth the results indicate that a high deposition temperature would be necessary in order to grow epitaxial films.

The resistivity of the as-deposited films were $95-200 \mu \Omega \mathrm{cm}$ which is considerably higher than the bulk value for $\mathrm{ZrB}_{2}$ but in the lower regime of other reported films grown by PVD. 


\subsection{Paper II}

The study reported in this paper was in part inspired by CVD processes previously used to grow epitaxial $\mathrm{ZrB}_{2}$ films where a deposition temperature of $900{ }^{\circ} \mathrm{C}$ was utilized and where substantial effort was made to ensure that the substrates were clean. In this paper an ultra-high vacuum system was used and $4 \mathrm{H}-\mathrm{SiC}(0001), \mathrm{Si}(111)$ and $\mathrm{GaN}(0001)$ on $4 \mathrm{H}-\mathrm{SiC}(0001)$ substrates was deposited by direct current magnetron sputtering from a compound source. The substrates were thoroughly cleaned including etching with hydrofluoric acid and outgassing in the system's load-lock. However, the deposition rate was substantially higher $(\sim 80 \mathrm{~nm} / \mathrm{min})$ compared to the CVD growth (0.3-1.4 $\mathrm{nm} / \mathrm{min})$. Also, the films grown in this study were considerably thicker.

Pole figure measurements showed that the films were epitaxial on $4 \mathrm{H}-\mathrm{SiC}(0001)$ and $\mathrm{Si}(111)$ but fiber textured on $\mathrm{GaN}(0001)$. TEM and electron diffraction confirmed that the film grew epitaxial all the way from the substrate interface to the surface of the $400 \mathrm{~nm}$ film. From TEM it could also be seen that the film grew columnar with the width of the columns being approximately $5 \mathrm{~nm}$. Results from reciprocal space maps also supported that the film consists of epitaxial columns of limited size. 


\section{References}

[1] Fleurence A, Yamada-Takamura Y. Scanning tunneling microscopy investigations of the epitaxial growth of $\mathrm{ZrB}_{2}$ on $\mathrm{Si}(111)$. Physica Status Solidi (C) Current Topics in Solid State Physics 2011;8(3):779-783.

[2] Fahrenholtz WG, Hilmas GE, Talmy IG, Zaykoski JA. Refractory diborides of zirconium and hafnium. J Am Ceram Soc 2007;90(5):1347-1364.

[3] Rahman M, Wang CC, Chen W, Akbar SA, Mroz C. Electrical Resistivity of Titanium Diboride and Zirconium Diboride. J Am Ceram Soc 1995;78(5):1380-1382.

[4] Pierson HO. Handbook of refractory metal carbides and nitrides. New Jersey: Noyes publications; 1996.

[5] Stroms EK. The refractory metal carbides. New York: Academic Press; 1967.

[6] Massalski TB, Murray JL, Bennett LH, Baker H editors. Binary Alloy Phase Diagrams. Ohio: American Society for Metals; 1986.

[7] Oder TN, Martin P, Adedeji AV, Isaacs-Smith T, Williams JR. Improved schottky contacts on n-type 4H-SiC using $\mathrm{ZrB}_{2}$ deposited at high temperatures. J Electron Mater 2007;36(7):805-811.

[8] Wright JS, Khanna R, Ramani K, Cranciun V, Singh R, Norton DP, et al. ZrB $2 / \mathrm{Pt} / \mathrm{Au}$ Ohmic contacts on bulk, single-crystal ZnO. Appl Surf Sci 2006 12/30;253(5):2465-2469.

[9] Khanna R, Ramani K, Cracium V, Singh R, Pearton SJ, Ren F, et al. ZrB 2 Schottky diode contacts on n-GaN. Appl Surf Sci 2006 12/15;253(4):2315-2319.

[10] Khanna R, Pearton SJ, Ren F, Kravchenko II. Stability of Ti/Al/ZrB $2 / \mathrm{Ti} / \mathrm{Au}$ ohmic contacts on n-GaN. Appl Surf Sci 2006 12/15;253(4):2340-2344.

[11] Kinoshita H, Otani S, Kamiyama S, Amano H, Akasaki I, Suda J, et al. Zirconium diboride (0001) as an electrically conductive lattice-matched substrate for gallium nitride. Jpn J Appl Phys Part 2 Letter 2001;40(12 A):L1280-L1282. 
[12] Tolle J, Roucka R, Tsong IST, Ritter C, Crozier PA, Chizmeshya AVG, et al. Epitaxial growth of group III nitrides on silicon substrates via a reflective lattice-matched zirconium diboride buffer layer. Appl Phys Lett 2003;82(15):2398-2400.

[13] Bera S, Sumiyoshi Y, Yamada-Takamura Y. Growth of single-crystalline zirconium diboride thin film on sapphire. J Appl Phys 2009;106(6).

[14] Fleurence A, Friedlein R, Ozaki T, Kawai H, Wang Y, Yamada-Takamura Y. Experimental evidence for epitaxial silicene on diboride thin films. Phys Rev Lett 2012;108(24).

[15] Hu C-, Chizmeshya AVG, Tolle J, Kouvetakis J, Tsong IST. Nucleation and growth of epitaxial $\mathrm{ZrB}_{2}\left(\begin{array}{lll}0 & 0 & 1\end{array}\right)$ on $\mathrm{Si}\left(\begin{array}{lll}1 & 1 & 1\end{array}\right)$. J Cryst Growth 2004;267(3-4):554-563.

[16] Tolle J, Kouvetakis J, Kim D-, Mahajan S, Chizmeshya AVG, Hu C-, et al. Epitaxial growth of $\mathrm{ZrB}_{2}(0001)$ on $\mathrm{Si}(111)$ for III-nitride applications: A review. Chinese Journal of Physics 2005;43(1 II):233-248.

[17] Roucka R, Tolle J, Chizmeshya AVG, Tsong IST, Kouvetakis J. Epitaxial film growth of zirconium diboride on $\operatorname{Si}(00$ 1). J Cryst Growth 2005;277(1-4):364-371.

[18] Sung J, Goedde DM, Girolami GS, Abelson JR. Remote-plasma chemical vapor deposition of conformal $\mathrm{ZrB}_{2}$ films at low temperature: A promising diffusion barrier for ultralarge scale integrated electronics. J Appl Phys 2002;91(6):3904-3911.

[19] Larsson T, Blom H-, Berg S, Östling M. Reactive sputtering of titanium boride. Thin Solid Films 1989;172(1):133-140.

[20] Helmersson U, Lattemann M, Bohlmark J, Ehiasarian AP, Gudmundsson JT. Ionized physical vapor deposition (IPVD): A review of technology and applications. Thin Solid Films 2006;513(1-2):1-24.

[21] Ohring M. Materials Science of Thin Films. 2nd ed.: Academic Press; 2002.

[22] Chakrabarti UK, Barz H, Dautremont-Smith WC, Lee JW, Kometani TY. Deposition of zirconium boride thin films by direct current triode sputtering. J Vac Sci Technol A 1987 March 1987;5(2):196-201.

[23] Voss L, Khanna R, Pearton SJ, Ren F, Kravchenko II. Use of TiB 2 diffusion barriers for $\mathrm{Ni} / \mathrm{Au}$ ohmic contacts on p-GaN. Appl Surf Sci 2006 11/30;253(3):1255-1259.

[24] X. Zou. Oxidation behavior of RF sputter deposited zirconium diboride thin films. San Jose State University; 1995.

[25] Takeyama MB, Noya A, Nakadai Y, Kambara S, Hatanaka M, Hayasaka Y, et al. Low temperature deposited $\mathrm{Zr}-\mathrm{B}$ film applicable to extremely thin barrier for copper interconnect. Appl Surf Sci 2009;256(4):1222-1226. 
[26] Shappirio JR, Finnegan JJ. Synthesis and properties of some refractory transition metal diboride thin films. Thin Solid Films 1983;107(1):81-87.

[27] Ignatenko PI, Terpii DN, Goncharov AA. Phase composition of films deposited by ZrB2 RF magnetron sputtering. Inorganic Materials 2003;39(5):464-468.

[28] Birkholz M. Thin Film Analysis by X-Ray Scattering. Weinheim, Germany: WILEY-VCH Verlag GmbH \& Co; 2006.

[29] Erni R, Rossell MD, Kisielowski C, Dahmen U. Atomic-resolution imaging with a sub-50-pm electron probe. Phys Rev Lett 2009;102(9). 